\title{
Exploring dairy producer and veterinarian perceptions of barriers and motivators to adopting on-farm management practices for Johne's disease control in Ontario, Canada
}

\author{
S. M. Roche, ${ }^{1,2}$ D. F. Kelton, ${ }^{2 *}$ M. Meehan, ${ }^{3}$ M. Von Massow, ${ }^{4}$ and A. Jones-Bitton ${ }^{2}$ \\ ${ }^{1}$ ACER Consulting, Guelph, ON, Canada, N1G 5L3 \\ ${ }^{2}$ Department of Population Medicine, University of Guelph, Guelph, ON, Canada, N1G 2W1 \\ ${ }^{3}$ Waireki Rd. Veterinary Clinic, Christchurch, New Zealand, 8053 \\ ${ }^{4}$ Department of Food, Agricultural, and Resource Economics, University of Guelph, Guelph, ON, Canada, N1G 2W1
}

\begin{abstract}
Motivating uptake of management change recommendations requires knowledge of the barriers and motivators influencing producer behavior. This study investigated dairy producers' and veterinarians' perceptions of the barriers and motivators influencing the adoption of Johne's disease (JD) control recommendations in Ontario, Canada. Eight focus groups, 6 with dairy producers and 2 with veterinarians, were conducted and thematically analyzed. Both producer and veterinarian groups identified physical resources (i.e., time, money, infrastructure) and producer mindset (i.e., perceived priority of JD, perceived practicality of JD control recommendations) as key barriers to adoption. Producers tended to prioritize JD control on their farm based on their lived experiences with JD and their view of the public's concern about JD. Many agreed that JD recommendations should focus on biosecurity more holistically and emphasize the broader health benefits of limiting calf exposure to many fecal-orally transmitted diseases. Producers also highlighted that some recommendations for on-farm change (i.e., keeping a closed herd, buying from low-risk herds) were unrealistic or too difficult to perform and often disrupted their habits or routine. In contrast, veterinarians suggested that most recommendations were practical and are routinely recommended. Participants suggested both extrinsic (i.e., incentives, premiums, penalties and regulations, and extension and communication) and intrinsic (i.e., pride and responsibility) methods for motivating producers. This study highlights the importance of producer mindset in on-farm change and offers insights into the attitudes and perceived barriers influencing on-farm change.
\end{abstract}

Received November 4, 2018.

Accepted January 14, 2019.

*Corresponding author: dkelton@uoguelph.ca
Key words: Johne's disease, farmer perception, qualitative, extension

\section{INTRODUCTION}

Johne's disease (JD) is a chronic wasting disease of dairy cattle and other ruminants that can result in decreased milk production, decreased fertility, and premature culling of animals (Sweeney et al., 2012). This production-limiting disease has also been implicated as a potential cause of Crohn's disease in genetically susceptible humans (Mishina et al., 1996; Naser et al., 2004; Chiodini et al., 2012; Sweeney et al., 2012). Thus, JD prevention and control at the farm level are important for ensuring healthy, productive dairy herds and producing safe dairy products for human consumption.

Current recommendations for the prevention and control of JD involve a combination of cow and wholeherd testing and the implementation of on-farm management practices to improve biosecurity (Sweeney et al., 2012). Numerous countries have implemented JD control programs, and many use veterinarian-administered risk assessments (McKenna et al., 2006; Nielsen, 2007; Collins et al., 2010; Barker et al., 2012). These risk assessments are used to highlight high-risk management practices for dairy producers and to recommend changes in on-farm management for JD control (Sorge et al., 2010a). Given that the efficacy of these programs is ultimately dependent on a producer's willingness to adopt farm-specific recommendations, it is concerning that research indicates poor producer adoption of JD control measures (Wraight et al., 2000; Jubb and Galvin, 2004; Ridge et al., 2005; Sorge et al., 2010a).

A producer's behavior and subsequent decision to adopt to recommendations to change their management are influenced by numerous factors. Many sociopsychological models have been developed to explain human behavior, and although no one model is universally subscribed to, their common constructs describe the 
influence of personal factors (e.g., attitude, perception, knowledge, opinion, beliefs, skills), interpersonal factors (e.g., veterinarian-producer communication, agricultural extension efforts, industry outreach), and external cues (Leeuwis and van den Ban, 2004; Boxelaar and Paine, 2005; Rehman et al., 2007; Pratt and Bowman, 2008) on behavior. Influencing producer behavior toward adopting on-farm practices for JD control is thus a complicated endeavor that requires knowledge of how to effectively inform, educate, and influence as well as an understanding of how and why producers behave the way they do (Garforth, 2011). To date, little research has been conducted to investigate dairy producer attitudes toward the barriers and motivators influencing the adoption of on-farm management practices for JD control. The goal of this study was to investigate dairy producers' and veterinarians' perceptions of the barriers and motivating factors for adopting on-farm changes for JD control in Ontario $(\mathbf{O N})$, Canada, to support future programs.

\section{MATERIALS AND METHODS}

\section{Study Design}

This qualitative study was designed to understand the factors that influence dairy producers to adopt recommendations to make on-farm changes for JD control and the context that results in these recommendations being applied or not. This study therefore uses a critical realist perspective (Maxwell, 2012) to explore the depth of producer perceptions and attitudes along with veterinarian perspectives about their dairy producer clients.

\section{Participant Recruitment}

Between October and December 2012, 6 focus groups were conducted with dairy producers residing in ON, Canada. Producer focus groups were held in 6 separate regions of ON (Woodstock, Seaforth, New Liskeard, Napanee, Winchester, and Navan), which were purposefully chosen based on a high density of commercial dairy farms in these regions. Using the central point of each region and the farm location coordinates and contact information from a current provincial database (Dairy Farmers of Ontario), geographic information system mapping was used to plot the locations of farms within a $10-\mathrm{km}$ radius. All producers in the sampling frames received a recruitment letter describing the details and objectives of the project. Approximately $1 \mathrm{wk}$ later, recipients of the letters were randomly selected using a random number generator and recruited via telephone. Either 9 or 10 participants were recruited for each focus group to help ensure a minimum attendance of 6 participants.

Two additional focus groups were facilitated with bovine veterinarians practicing in $\mathrm{ON}$. Veterinarians registered to attend an annual bovine veterinarian meeting taking place in Guelph, ON, were recruited for each focus group via email. Veterinarians expressing interest were contacted by telephone to confirm participation. An honorarium of $\$ 50$ was paid to all focus group participants for their participation.

\section{Data Collection}

A trained moderator led all focus group discussions, and an assistant made written notes summarizing the discussion and group dynamics. The age and sex of participants were recorded upon focus group attendance. Additionally, the herd JD status of participants' farms was determined by retrieving each farm's most recent JD milk ELISA test result, if one had been performed, through the Ontario Johne's Disease Education and Management Assistance Program database.

Focus group sessions were roughly $2 \mathrm{~h}$ in duration and were audio-recorded and professionally transcribed to facilitate analyses. A pretested, structured questioning route was developed according to Krueger and Casey (2008) using a combination of primary questions and probes to elicit further detail (Appendices A and B). Questions were intended to elicit information about participants' general thoughts about JD, their perceived barriers to adopting recommendations for JD control, and opinions about how to motivate producers to implement JD control recommendations.

\section{Qualitative Analysis}

Transcripts were checked against the original audio recordings for accuracy. Our approach to coding was based on Creswell and Miller (2000) and DeCuir-Gunby et al. (2011). Briefly, a coding scheme for analysis was created by having 2 coders who had received formal training in qualitative analysis [authors SR (coder 1) and MM (coder 2)] separately code (i.e., assign descriptive labels to each statement to categorize content) a transcript line by line and then comparing and revising codes based on discussions between the 2 coders. The subsequent codebook was then applied to the remaining transcripts by coder 1 . Coders met on a weekly basis during the coding process to discuss the applicability of the developed codebook, determine and decide on necessary revisions or additions to codes, and debrief on the emerging findings. A finalized version of the codebook was prepared once all transcripts had been coded. Each transcript was then reviewed a final time 
with the final codebook to ensure that all codes had been appropriately and consistently applied. With coding complete, codes from all transcripts were compiled, categorized, and thematically analyzed to generate themes and subthemes, as described by Braun and Clarke (2006). Data cleaning, coding, and analysis were performed in ATLAS.ti (ATLAS.ti Scientific Software Development, Berlin, Germany). Select verbatim quotations have been included in the text as exemplars of subthemes; square brackets have been inserted in areas to provide the reader with context.

\section{Validity}

Issues of descriptive validity were addressed by cross-referencing all transcripts with the original audio recordings. Interpretive validity was addressed through debriefing between the moderator and assistant immediately after each focus group. Weekly meetings between coder 1 and coder 2 were also held to discuss the analysis and to review and refine codes and themes as they developed. Focus group participants were sent letters with brief summaries of the key themes of the workshop and were asked for any final feedback via telephone. Last, an ongoing log of notes was taken to describe and capture the research process in the form of an audit trail. The Research Ethics Board of the University of Guelph approved this study (protocol no. 11AP009), and all participants provided informed written consent.

\section{RESULTS}

\section{Participants}

A total of 39 dairy producers, 32 male and 7 female, participated in the focus groups. Producer ages ranged from 27 to $58 \mathrm{yr}$, with an average age of $36 \mathrm{yr}$. Herd sizes ranged from 35 to 450 milking cows, with an average of 120. Among those who had a JD milk ELISA test performed within the previous 12 mo $(\mathrm{n}=35)$, $42.9 \%(15 / 35)$ had at least 1 test-positive cow. A total of 8 veterinarians, 7 male and 1 female, participated in the focus groups, with ages ranging from 29 to $57 \mathrm{yr}$.

\section{Thematic Analysis}

Two overarching themes, each with multiple subthemes, were developed from the qualitative analysis of the focus groups: (1) barriers to adoption of JD control measures and (2) motivation to adopt JD control measures. Figure 1 provides a thematic map, which visually depicts the themes, subthemes, and relationships identified.

\section{Theme 1: Barriers to Adoption of JD Control Measures}

Several subthemes related to barriers influencing the adoption of on-farm JD control measures were identified. Physical resource limitations were identified across all dairy producer and veterinarian focus groups. Several other subthemes, all related to aspects of a producer's mindset influencing their decision to prioritize the adoption of JD control recommendations, were identified; specifically, producer perception of JD as a problem on the farm, the public's concern about JD, and the perceived practicality of JD control recommendations were important aspects of a producer's mindset influencing their decision to prioritize the adoption of JD control recommendations.

Physical Resources. Focus group participants were quick to point out that their time, money, and existing facilities were key physical resources that inhibit adoption of JD control practices on their farms. Producers were particularly focused on how a combination of limited time and money and current barn size and layout were important barriers to adoption: "Most of these things relate back to money and time. Other than money, time is a huge factor for this stuff. I've only got two hands and so much time in a day, right? And I've only got a set amount of money to deal with a number of different issues, so they are definitely some of the main barriers . . . cash and time, you know?" Another producer echoed these comments, saying, "Nobody wants to spend more than they have to, especially if they don't see a benefit from it. Like [JD control] doesn't raise your cow's price if you say she's Johne's negative, right, so I have to consider how much time it's going to take, how much money, and if I have the space to realistically make the changes."

Most veterinarians expressed similar comments: "If my clients don't really want to do the change then they say, 'oh, that sounds like it costs too much money and will probably take up too much time,' even though most of these things are pretty basic and don't cost a lot." Another veterinarian commented, "I usually hear stuff like, 'It's a space issue . . . My facility is only so big and the layout won't work for what you're suggesting,' or they'll comment on how some recommendations are just going to take too much time or even cost too much. So, it's pretty much time, money, and space, you know."

Is JD a Problem on My Farm? Dairy producer opinions on how JD control should be prioritized on the farm were mixed, with some participants ranking JD control as a low priority, whereas others suggested it was a higher priority for them. Participants often rationalized their opinion by describing their perception of JD as a problem on their farm. Many for whom JD 
Theme 1: Barriers to Adoption of JD Control Measures

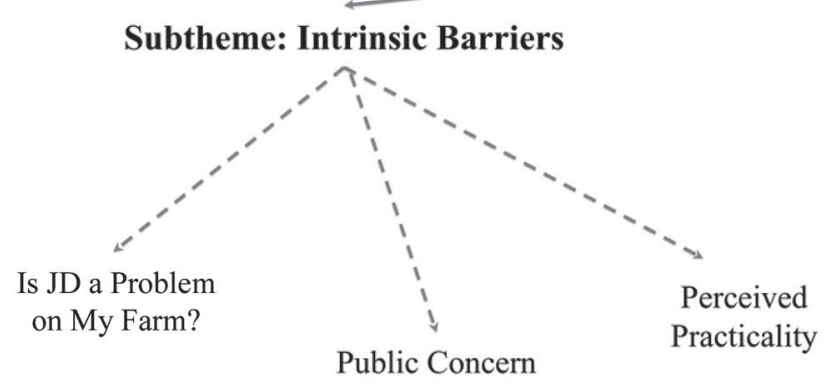

Subtheme: Intrinsic Barriers

Public Concern
Perceived

(1)

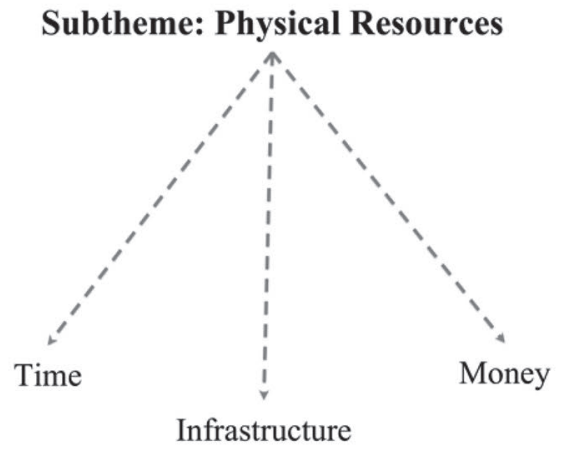

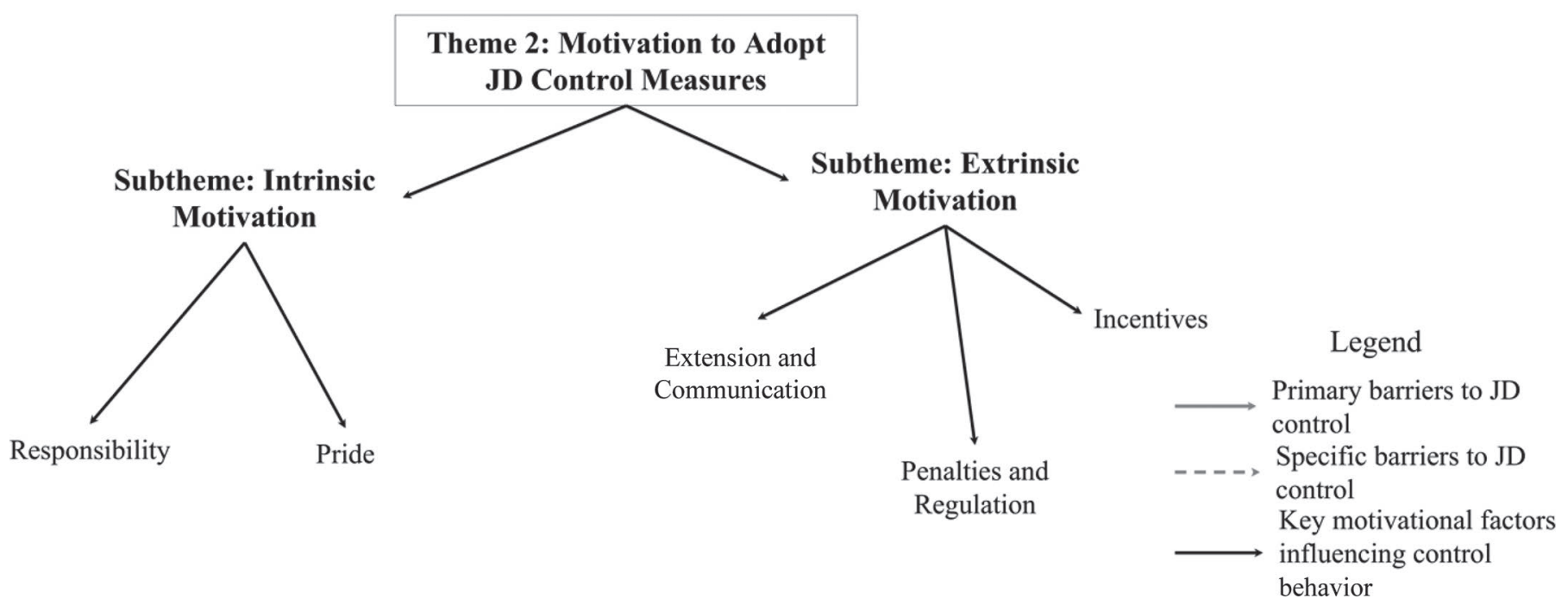

Figure 1. Thematic map produced from the thematic analysis of data on perceived barriers and motivators for the on-farm adoption of Johne's disease (JD) control recommendations collected during 6 dairy producer and 2 veterinarian focus groups conducted in Ontario, Canada (October to December 2012). Bolded themes and subthemes are discussed in the text.

was not a priority described how JD was not an issue on their farm; for example, "For us, it's a really low priority . . . like near the bottom . . . we don't see [JD] on our farm." Another producer explained, "I don't lay in bed at night thinking about how I'm going to deal with Johne's on my farm . . . There are a lot of other worries before that comes through for me. It's just not a priority you know, it's just not an issue that we're dealing with on our farm." Veterinarians expressed similar opinions when discussing how they thought dairy producers prioritized JD on the farm. One veterinarian suggested, "They certainly wouldn't put it in their top five diseases to worry about," and another said, "A lot of things are on their minds ahead of Johne's, except for the guys that actually have it."
Other producers considered JD to be an important priority for their farm. These participants typically had personal experience with JD, often describing personal anecdotes of JD on their farm, or had known someone who was affected: "It's a big concern for us . . . . We've had [JD] in the past and we know others who are dealing with it. So, it's definitely something we're concerned about on our farm and actively trying to manage." Other producers described JD control as an important issue from a more general biosecurity standpoint, explaining, "To me it's one of 10 important issues. There's all kinds of things you have to maintain and keep an eye on . . . whether it's mastitis, Johne's, or whatever... . To me it's one of a 10-piece puzzle to disease control. So, it's prioritized just as much as any one of a number of other 
diseases, you know. Because if you slip up on any one of these areas, you could be in big trouble. . . so it's something we need to be worried about."

Public Concern. The majority of producers that expressed little concern over JD on their farm also tended to express less concern about the public perception of JD, frequently questioning the severity of JD in Canada: "It's much more of an American issue . . you just tend to hear more from down there. The information we get here is more American than it is Canadian, so I think it's less of an issue for us." Another producer commented, "I think if it was a problem, we'd hear about it more . . frankly, if it was a problem then we'd have heard more about cases in Ontario, and the public would be talking about it, but I'm not hearing much, so I'm not really concerned." However, the majority of veterinarians expressed more concern when discussing public perception and a potential link between JD and Crohn's disease. One veterinarian expressed this well: "You know, if a big news story, or something very public comes out, it won't matter if 10 or 100 have it. . . . If there's a negative perception from the consumer, or a perception that drinking milk can be harmful to people's health, then we've got a problem. So, the whole MAP [Mycobacterium avium ssp. paratuberculosis $]$ and Crohn's thing could definitely turn into an issue, whether there's a real link or not."

Producers who expressed a concern for biosecurity also expressed concern for the public's perception of JD. In particular, they were concerned about the potential link between JD and Crohn's disease and public health safety; for example, "If the public thinks that it's an issue, then this potential link to Crohn's could be a big issue for us, no doubt about it. Consumers want a safe and quality product.... Johne's control is important from that point of view for sure." A producer from another focus group similarly commented, "Consumer perception of our industry, of our product is, kind of paramount. My career is producing milk, you know, so I think it's pretty important that we do everything we can to make sure the consumer views us in a positive light."

Perceived Practicality. Producers and veterinarians often stated that a producer's perception of the practicality of JD control recommendations was a barrier to change. Many producers simply suggested that implementing JD control recommendations are too difficult. One producer stated, "To me, most of these recommendations are unrealistic, and are not going to happen without a big change. You know, they're tough to do. Vets are great for telling us what we need to do, but getting it done is another story."

In particular, producers focused on the recommendation to keep herds closed or buy cattle from low-risk herds: "I mean, if you need cows, if you need the milk, you're going to buy, right? You're not going to start worrying about Johne's if you need the milk . . . . If you need them, you'll buy them." Other producers acknowledged this barrier and the difficulty in assessing the JD status of cows for sale, stating, "We have to pay the bills, so we're bringing in cows if we need them, that's all there is to it. And when we talk about low-risk herds, well, it's not like everyone has their Johne's tests posted at the end of the driveway."

Other producers commented on the practicality of the recommendation to remove calves from the dam immediately after birth, explaining, "The biggest issue is removing calves at night time for me . . it's just not practical. I'm not going to go out and take a calf away in the middle of the night, she's going to stay with the cow."

In contrast, the majority of veterinarians described the recommendations as practical, with comments such as, "Oh yeah, I think probably every one of these things have been on my list of things to do for producers. They definitely seem reasonable to me," and "Everyone's got limitations, but most of them I think are pretty easy, you know, if the farmer is serious about reducing Johne's disease on the farm. I think most of us are pretty realistic when giving recommendations."

Producers and veterinarians often described how a producer's routine and habits might affect their perception of the practicality of JD control recommendations. One producer explained, "You know, it's tough when you've got a set routine and everyone knows their role. Changing that up and taking on new tasks can be tough to do when it disrupts the flow." Veterinarians tended to agree, with one veterinarian commenting, "It's the way they've always done it and they don't seem to have a problem with Johne's doing things this way, so they say 'Why would I change?' They look at the recommendations and think, 'This is going to upset my routine, and for what?'"

\section{Theme 2: Motivation to Adopt JD Control Measures}

Both dairy producers and veterinarians described factors that they thought would motivate producers to adopt on-farm JD control measures. These were categorized as intrinsic motivation and extrinsic motivation. Intrinsic motivation was further broken down into subthemes of pride and responsibility, whereas incentives, penalties and regulations, and extension and communication were identified as extrinsically motivating factors.

Intrinsic Motivation: Pride. A small number of producers felt that a producer's pride as an animal caretaker was an important motivating factor for onfarm changes. One producer explained, "You know, you walk through your group [of cows] and you see they're all 
healthy and nice looking . . . you feel proud . . . and you think, wow, that's because of my hard work, you know, it's important to me and it shows, I think." Another producer agreed, and responded, "You see the benefits of good management practices that come with trying to control Johne's, because they have other benefits on the farm, like faster heifer growth and health. For me, making sure my herd is healthy is a source of pride, you know. It's something me and my family is in control of, so seeing a healthy group makes me proud because I know I had a role to play. So, preventing or controlling Johne's is big for me."

Intrinsic Motivation: Responsibility. Several producers highlighted the responsibility that comes with creating a food product; for example, "We as Canadian milk producers, we say we have a safe product, you know, so we have to do tests and make sure we're dealing with [JD], because otherwise consumers say 'What's going on with Johne's disease?' and a link to Crohn's won't be pretty." A producer from another focus group suggested, "Keeping the consumer comfortable with the product that we're providing them is paramount. Like, there's concern that there's people linking Crohn's and Johne's, so we need to make sure we're on top of this and keep the consumer safe and happy." Although the majority of discussions on responsibilities revolved around those to the consumer, a small number of producers also acknowledged a responsibility for animal health. One producer summarized this well: "A lot of these control measures you strive to do anyways, whether you have Johne's or not . . . . You want the best for your cattle, you know. Like, we have a responsibility for our animals and their health, right, so controlling Johne's is on us."

Extrinsic Motivation: Incentives. Many producers described the potential value of incentives for adopting JD control. Free JD testing was proposed as a useful incentive, with one producer commenting, "Well, if re-testing [for JD] came at no cost to the farmer, I'm sure a lot more farmers would be willing to do that. I would be much more willing to consider re-testing on an annual basis if the test were subsidized, that's for sure." With free testing having been offered in ON previously, one veterinarian commented, "The free testing helped tremendously; it's definitely helped create awareness, which has helped with implementing some of these changes." Veterinarians also discussed the value of financial incentives and subsidies for making on-farm changes. One veterinarian suggested, "If [producers] don't really want to do the change then they say, 'Oh, that sounds like it costs too much money,' even though most of these things are pretty basic and don't cost a lot. I think if you were to provide some sort of funding, they might be a little more motivated."
Extrinsic Motivation: Penalties and Regulations. Although veterinarians did not discuss the potential effect of penalties and regulations on adoption, producers explained how they can be important for motivating change. One producer commented, "We can motivate some guys with a premium, or some kind of cash incentive for making changes, and we motivate the rest by offering a penalty if they don't." Another producer similarly stated, "Meeting them with the carrot or the stick... either you take the carrot option or we'll follow up with the stick, your choice. It's our industry, we need to make sure everyone meets a standard, you know?"

Many producers also focused on the potential link between JD and Crohn's disease when rationalizing penalties and regulation. One producer suggested, "It's just like the somatic cell count penalty coming down, right . . . it's about milk quality in that case and it's about milk safety in this case. People aren't going to change until it hurts, so imposing some sort of penalty is probably the next step to make sure our food products meet standards."

Producers identified industry as the primary regulator for JD control. Several producers perceived that the Canadian Quality Milk (CQM) program (a mandatory food-safety program) would be a logical option for regulating JD control, with one producer stating, "It would be easier to address Johne's if it was in the CQM program," and another commented, "It should definitely be tied to CQM . . . . It should be a criteria under that program somewhere." One producer provided a good summary of these discussions: "See, maybe they need to take it a step further and say, if you want to be a Class A milk producer, then these are the requirements, through the CQM, that you need to do. Maybe it's the [JD] test and doing a risk assessment or something, verified by CQM to make sure these [protocols] are in place. Then the guys that are dragging behind and living in the dark thinking they don't have a problem, well, then they either deal with it or maybe choose another career." However, several producers viewed these suggestions negatively, stating, "Yeah, that's all we need, more intrusion into our lives," and "[Regulation] is just going to bring more restriction." Despite these comments, many discussions revolved around a need for a structured method of penalizing or regulating JD control.

Producers also discussed the potential for mandatory JD testing, with comments such as, "Mandatory bulk testing is the only way to open somebody's eyes up because it's the ones that say 'Ah, don't worry, we're not going to go testing for something we don't have .. .'; those are the ones that need to open up. So . . maybe we need mandatory bulk testing and if you're positive three 
times, then you get a penalty," and "I say make testing mandatory and you know what, it will maybe sharpen guys up a little bit. Maybe they won't put their positive cows up at the sale barn and our chances of bringing it home will be a lot less."

Extrinsic Motivation: Extension and Communication. Veterinarians commonly discussed the role of extension and communication to motivate producers and emphasized the importance of group discussion and peer-to-peer learning. One veterinarian commented, "The best meetings I've had was where there was no speaker and the farmers were just talking to each other." In response, another veterinarian commented, "I've heard that [meetings with no experts] are the meetings that the farmers said they don't want; they almost always want to get another speaker in. For them it's easier, right, they just get to sit and listen to somebody, but those sessions we have where we don't have a speaker, those are the meetings the farmers are still talking about, because they remember a lot of those things that they discussed amongst themselves and that really stuck."

Producers focused more on the content that should be provided through extension and communication efforts. More specifically, they suggested that messages should highlight the negative consequences of JD and the positive benefits of change; for example: "If you can't come to me and show me how changing something is going to make me produce more, improve herd health, or some small way make me more money, then, I'm probably not going to be that motivated to change it." Another producer commented, "If you were to show producers what Johne's could do to your herd, that would motivate someone to change, you know, because if Johne's didn't kill cows, we wouldn't worry about it at all. But it's the potential loss, be it cows or milk, that is going to motivate change."

Many other producers felt that promoting calf health more holistically was a better motivator than simply recommending changes for JD control. Two producers described this idea well: "You're not just preventing Johne's you know . . . you're preventing scours and everything else with it. That's an important message to motivate guys to change." Another discussion led a producer to comment, "I wouldn't tell someone to make these changes just for Johne's; I think it's important to highlight the other issues on the farm. You know, the ones they see and deal with more regularly, like scours and stuff like that. You want to talk more about standard procedures and discipline, and if that happens, you take care of Johne's too." Veterinarians echoed these comments, stating, "I approach Johne's from a more general stance. Disease prevention in general . . . it's all about preventing calf and manure contact in the first two weeks of life, you know."

\section{DISCUSSION}

\section{Barriers to Adoption of JD Control Measures}

Is JD a Problem on My Farm? Dairy producer perceptions about the priority of JD control were varied and were largely driven by their lived experiences with JD (i.e., current and previous on-farm JD status). Almost $60 \%$ of producers in this study did not have a test-positive animal for JD on their most recent JD test, which likely contributed to the perception among many producers that JD was not a priority on their farm. Sorge et al. (2010a) showed similar perceptions among Canadian dairy producers, where almost $75 \%$ of respondents reported not seeing JD as a problem for their farm. Similar findings have also been observed in New Zealand (Norton et al., 2009), the United Kingdom (Heffernan et al., 2016), and Ireland (McAloon et al., 2017), where farmers of herds believed to be uninfected tend to view recommended management practices as not worth adopting unless a change in disease status is observed. Leeuwis and van den Ban (2004) suggested that risk perception depends on, among other factors, visibility, magnitude, and the directness and duration of consequences. This may help explain the perceptions of JD control as a low priority reported by producers in this study: JD is caused by a microscopic bacterium whose signs of infection are largely absent among most infected animals (poor visibility); a relatively low number of animals are infected at one point in time (low magnitude); and JD takes years to manifest clinically (seemingly indirect and long duration). As such, it seems reasonable that many producers' perceived risk of JD would be low. Efforts to influence adoption among producers with these negative perceptions may be more effective if they focus on the benefits of reducing the effects of other fecal-orally transmitted diseases of cattle, such as Escherichia coli, Campylobacter spp., Salmonella spp., and Cryptosporidium spp., which can be prevented and controlled through the same approaches used to control JD. As the negative health effects of calf infection with these latter bacteria are more readily visible than JD, producers may attribute higher risk to these diseases and thus be more open to change. As a result, producers making changes to address these other bacteria would also have a direct positive effect on JD control without explicitly changing their behavior for JD control. Ritter et al. (2017) also highlighted that differences in farmers' perception of the threshold at which an issue becomes a problem for their operation (their "frame of reference") are an important consideration that is often associated with their willingness to adopt a given behavior. Efforts to address these concerns would then involve using bench- 
mark tools or providing guidelines to alter their frame of reference (Ritter et al., 2017).

Public Concern. Producers' prioritization of JD control also appeared to be related to their concerns about the public perceptions of JD and the potential link between JD and Crohn's disease. Several participants felt it was not a concern due to a lack of media attention and discussion among their peers, whereas many other participants believed that JD is a problem due to its potential to negatively influence consumer opinion and consumption. These concerns were similar to findings from Sorge et al. (2010a), who found the potential association between JD and Crohn's disease to be a significant motivator for Canadian dairy producers to join a JD control program. Although evidence for this link is controversial, Sweeney et al. (2012) suggested that there is moderately strong evidence of a causal relationship between Mycobacterium avium ssp. paratuberculosis (MAP) and Crohn's disease in genetically susceptible individuals. A change in milk consumption or demand of milk products as a result of a perceived threat from JD would affect all dairy producers regardless of on-farm JD status. This message may serve as a powerful motivator to influence change among those who do not feel that JD is a problem on their particular farm.

Perceived Practicality. The perceived practicality of JD control recommendations was another barrier to change identified in this study. Many producers who felt that JD prevention was not a priority tended to question the practicality of some recommendations, often in terms of time and money. Garforth et al. (2013) reported that perceived practicality was an important factor influencing adoption of biosecurity recommendations and that perceptions of disease risk are often directly linked to perceptions of the specific recommendations. McAloon et al. (2017) reported that JD recommendations provided to Irish farmers were often viewed as impractical and were contrary to or inconsistent with their current knowledge of calf health management. Ritter et al. (2017) further explained that producers commonly assess recommended changes according to their available resources, particularly time, money, and space. They suggest the use of structured risk assessments, providing tailored recommendations, and sharing stories of successful implementation to improve perceived practicality. In this study, many producer criticisms referred to the participants' limited time or level of control over the specific practice. Sorge et al. (2010a) reported similar results, concluding that one of the main reasons for noncompliance among Canadian dairy producers was the perception that practices were unnecessary or too challenging to implement. Interestingly, most veterinarians perceived JD control recommendations as reasonable and feasible and suggested that the main barrier to adoption was producer attitude. These findings highlight that producers and veterinarians often have conflicting perceptions on the practicality of JD control measures. It is therefore important to inform both producers and veterinarians of these differences and focus on effectively communicating the value of making on-farm changes for JD control, whether the focus is on the control of JD specifically or improving biosecurity to prevent and control a variety of other calf diseases.

\section{Motivation to Adopt JD Control Measures}

Incentives. Producers perceived that free JD testing would motivate the adoption of JD control management practices. This coincides with the identification of money as a barrier to adoption as well, suggesting that free testing might eliminate financial barriers. Many of the provincial JD control programs in Canada, and programs worldwide, have implemented some form of subsidized testing (Barker et al., 2012; Harrison, 2013). However, many producers declined these opportunities even when fully subsidized. For example, only $52 \%$ of 4,158 eligible dairy herds in ON took advantage of free JD testing offered by their JD control program (OJEMAP, 2013). Furthermore, as might be expected, many of the world's control programs have experienced a drop-off in routine JD screening as subsidies were removed and the cost of testing was put back on the farmer (Harrison, 2013). The lack of participation in free testing and the subsequent drop-off in participation upon the removal of testing subsidies suggest that, generally, producer behavior changed without a change in attitude. When this occurs, behaviors are generally short lived (Pike, 2008; Sasaki, 2012), which ultimately compromises the long-term efficacy of these programs. Therefore, the provision of incentives such as free testing opportunities may be insufficient as standalone measures to facilitate sustained change.

Penalties and Regulation. Dairy producers in this study felt that financial premiums for MAP-free milk and penalties for milk containing MAP would serve as strong motivators for producers to adopt recommendations for JD control. The use of premiums and penalties to motivate producers has been widely implemented and researched in the context of mastitis control (Valeeva et al., 2007; Nightingale et al., 2008; Jansen et al., 2009). Jansen et al. (2009) reported that Dutch farmers felt that receiving premiums for low bulk-tank SCC motivated the uptake of on-farm control measures; however, Valeeva et al. (2007) suggested that Dutch farmers were more motivated by a price decrease for poor-quality milk (high bulk-tank SCC). 
Further evidence suggests that the combination of a penalty program for low-quality milk and a premium program for high-quality milk provided a strong incentive for American farmers to improve on-farm mastitis management (Nightingale et al., 2008). Thus, there appears to be value in the use of premiums, penalties, or both to motivate producers to change. It is important to note, however, that similar to incentives, this type of extrinsic motivation does not directly aim to influence producer attitudes or perceptions.

Some producers also rationalized the need for monitoring and regulating JD in Canada given the potential food safety issues related to Crohn's disease and human health. They further expressed interest in incorporating this into an existing monitoring program, the CQM. The CQM uses a hazard analysis critical control points approach to food safety, which focuses on preventing and minimizing the risk of food safety hazards (DFC, 2013). Although not currently designed to assess JDspecific risks, programs like the CQM may provide viable opportunities to monitor or enforce JD-related practices, such as testing and culling protocols. It may be more likely, however, that any industry-driven push to monitor and regulate JD would come in the form of an independent certification program. Nielsen (2011) reported that Danish producers expressed a desire for a JD certification program; however, challenges in declaring a herd to be free of MAP infection has led countries such as Canada (CAHC, 2006) and Denmark (Sergeant et al., 2008) to shy away from establishing a national certification program. Although some countries, including Australia, the Netherlands, and the United States, have implemented herd certification programs for JD (JIC, 2010), further evaluation of the voluntary JD control programs currently in place in Canadian provinces is needed before further monitoring, regulation, or certification can be considered (CAHC, 2006).

Extension and Communication. Veterinarians in this study regarded group discussion and peer-to-peer learning as valuable motivators for change. Agricultural extension research suggests that bottom-up approaches, which use producer-centered, participatory group approaches, are more effective in influencing change among farmers (Andreata, 2001; Fulton et al., 2003). The ability of these approaches to address the social factors influencing behavioral change has resulted in greater levels of adoption of on-farm mastitis control practices in Denmark (Vaarst et al., 2002) and JD control practices in Denmark (Trier et al., 2012), Australia (Kingham and Links, 2012), and Canada (Roche et al., 2015). Therefore, group approaches can be instrumental in motivating on-farm change for JD control and should be considered useful strategies to include as part of the communication tools used in a control program. Ritter et al. (2017) describes the importance of using several tools to communicate with producers in an effort to consider different learning preferences and ensure that the program has the potential to deliver information to many farmers at once (using mass and social media tools) and to take individual circumstances into account.

Pride and Responsibility. The findings suggest that producers' pride and perceived responsibility are motivating factors for change. For some, these intangible, or intrinsic, factors were important considerations in their decision to adopt JD control measures. Interestingly, Valeeva et al. (2007) reported that for Dutch dairy farmers, nonmonetary factors, such as internal esteem and taking pleasure in healthy animals on the farm, were equally as motivating as monetary factors to improve mastitis management. McAloon et al. (2017) also reported that decisions to adopt recommendations for JD control among Irish dairy producers were influenced by the level of pride they associated with specific actions (cultural capital) and the value they place on social relationships with others (social capital). In other words, producers are driven and influenced by a desire to feel like, and be viewed as, doing a good job or being a "good farmer."

Producers in this study also felt they were responsible for producing safe food products and maintaining animal health. Ellis-Iversen et al. (2010) similarly reported that almost all English and Welsh cattle farmer respondents believed they had a social responsibility to produce safe products and control zoonoses on their farms. Awareness of animal welfare has also been reported to be an important motivator for adopting JD control practices for dairy producers (Hop et al., 2011). Ritter et al. (2017) highlighted that farmer perception of responsibility is an important driver of behavior and that farmers are often more inclined to assume responsibility when it is part of a joint effort that involves other industry stakeholders, such as processors. Future control programs would therefore benefit from establishing partnerships with multiple members of the value chain and communicating to farmers about their commitments to supporting JD control. Furthermore, JD control programs, monitoring, and regulatory decisions in particular can benefit by addressing these intrinsic motivations, as they have been shown to both motivate and inhibit producer participation. For example, Hood and Seedsman (2004) reported that producers in an Australian JD control program expressed lowered self-esteem when their herds were identified as being infected with JD. Consequently, producers may be wary of participating in future JD control programs for fear of a negative stigma associated with a JD-positive herd status. In contrast, participation in JD control 
programs may result in increased self-esteem and pride among farmers who realize improved herd health as a result of making on-farm changes (Benjamin et al., 2010). Producers taking pride in herd health may also be more motivated to make changes to maintain or achieve a JD-negative status and improve overall herd health (Gunn et al., 2008). Therefore, future control programs should focus on communicating with producers about their pride and perceived responsibility with respect to their herd and the effect of disease. By focusing on these intrinsic motivators, control programs may be able to influence more sustainable change among producer populations.

A limitation of this study is the number of focus groups conducted for each of the populations of interest (i.e., producers and veterinarians), which were limited based on budgetary constraints. Without such limitations, focus groups would ideally have been carried out until saturation of the data had been achieved. Focus groups were deliberately chosen over individual interviews as our data collection method to capture individual producer attitudes and opinions as well as the interactions and dialog between producers. Although every effort was made to ensure mutual respect and equality among participants (by clarifying that all focus group discussions were to remain private and confidential, that there were no right or wrong answers, and that all perceptions, attitudes, and opinions could be expressed free from judgment), dairy producer participants may have been hesitant to discuss their personal on-farm issues with respect to JD due to concern over what other group members might think and a perceived loss in social capital (Heffernan et al., 2016; McAloon et al., 2017). As a result, it is possible that producers in this study may have deliberately biased their responses by providing socially desirable answers to questions about on-farm disease status or prevention and control practices.

\section{CONCLUSIONS}

This study investigated ON dairy producer and veterinarian perceptions of the barriers and motivators influencing the adoption of JD control recommendations. Although a lack of physical resources (i.e., time, money, and infrastructure) was considered to be an important barrier to on-farm change, participants also identified the significance of several barriers related to producer mindset, which related to the perception of JD as a problem on the farm, public concern about JD, and their perception of the practicality of JD control recommendations. The lived and shared JD experiences of producers tended to influence their perception of JD as an on-farm problem, with many of those who had not personally dealt with JD being generally unconcerned about the disease. Future control programs for JD control should take a multitool approach to change, exploring the use of incentives, penalties, and extension options as well as modifying their messaging to share JD experiences and express a more holistic stance on biosecurity by highlighting the indirect health benefits of JD control as a result of limiting calf exposure to other fecal-orally transmitted diseases.

\section{ACKNOWLEDGMENTS}

This work was supported by the Knowledge Translation and Transfer Funding Program of the Ontario Ministry of Agriculture, Food, and Rural Affairs/University of Guelph Partnership (Guelph, ON, Canada).

\section{REFERENCES}

Andreata, S. M. 2001. Learning from the group: A case study of the focus farm project in Gippsland, Victoria. MSc Thesis. University of Melbourne, Melbourne, Australia.

Barker, R. A., H. W. Barkema, G. Fecteau, G. P. Keefe, and D. F. Kelton. 2012. Johne's disease control in Canada - Coordinated nationally-Delivered provincially. Accessed Feb. 17, 2014. http:// manitobaholsteins.ca/my_folders/pdf/CJDI-_ICP_Australia_12 .pdf.

Benjamin, L. A., G. T. Fosgate, M. P. Ward, A. J. Roussel, R. A. Feagin, and A. L. Schwartz. 2010. Attitudes towards biosecurity practices relevant to Johne's disease control on beef cattle farms. Prev. Vet. Med. 94:222-230.

Boxelaar, L., and M. Paine. 2005. The social dimensions of on-farm change to improve water quality and biodiversity. A report prepared for Dairy Australia. Innovation and Change Management Group, Land and Food Resources, University of Melbourne, Melbourne, Australia.

Braun, V., and V. Clarke. 2006. Using thematic analysis in psychology. Qual. Res. Psychol. 3:77-101.

CAHC (Canadian Animal Health Coalition). 2006. Canadian Johne's disease initiative overview. Accessed Feb. 17, 2014. http:/ www.google.ca/url?sa=t\&rct $=j \& q=\& e s r c=$ $\mathrm{s} \&$ source $=$ web \& $\mathrm{cd}=2 \&$ ved $=0 \mathrm{CC} 8 \mathrm{QFj} \mathrm{AB} \& \mathrm{url}=\mathrm{http} \% 3 \mathrm{~A}$ $\% 2 \mathrm{~F} \% 2 \mathrm{Fwww}$.animalhealth.ca $\% 2 \mathrm{FDocument}-$ Item .aspx $\% 3 \mathrm{Fid} \% 3 \mathrm{D} 489 \& \mathrm{ei}=1 \mathrm{ITPUtTnE}$ SqsASqtICIDA \& usg $=$ AFQjCNGzXc58aljoBo2kjaQni0ezAOwirA\&bvm=bv.59026428,d .cWc.

Chiodini, R. J., W. M. Chamberlin, J. Sarosiek, and R. W. McCallum. 2012. Crohn's disease and the mycobacterioses: A quarter century later. Causation or simple association? Crit. Rev. Microbiol. 38:52-93.

Collins, M. T., V. Egglestone, and E. J. B. Manning. 2010. Successful control of Johne's disease in nine dairy herds: Results of a six-year field trial. J. Dairy Sci. 93:1638-1643.

Creswell, J. W., and D. L. Miller. 2000. Determining validity in qualitative inquiry. Theory Pract. 39:124-130.

DeCuir-Gunby, J. T., P. L. Marshall, and A. W. McCulloch. 2011. Developing and using a codebook for the analysis of interview data: An example from a professional development research project. Field Methods 23:136-155.

DFC (Dairy Farmers of Canada). 2013. Canadian quality milk. Accessed Feb. 17, 2014. http://www.dairyfarmers.ca/what-we-do/ programs/canadian-quality-milk. 
Ellis-Iversen, J., A. J. Cook, E. Watson, M. Nielen, L. Larkin, M. Wooldridge, and H. Hogeveen. 2010. Perceptions, circumstances and motivators that influence implementation of zoonotic control programs on cattle farms. Prev. Vet. Med. 93:276-285.

Fulton, A., D. Fulton, T. Tabart, P. Ball, S. Champion, J. Weatherley, and D. Heinjus. 2003. Agricultural Extension, Learning and Change. Rural Industries Research and Development Corporation, Kingston, Australia.

Garforth, C. J. 2011. Effective communication to improve udder health: Can social science help? Pages 55-66 in Udder Health and Communication. H. Hogeveen and T. J. G. M. Lam, ed. Wageningen Academic Publishers, Wageningen, the Netherlands.

Garforth, C. J., A. P. Bailey, and R. B. Tranter. 2013. Farmers' attitudes to disease risk management in England: A comparative analysis of sheep and pig farmers. Prev. Vet. Med. 110:456-466.

Gunn, G. J., C. Heffernan, M. Hall, A. McLeod, and M. Hovi. 2008. Measuring and comparing constraints to improved biosecurity amongst GB farmers, veterinarians and the auxiliary industries. Prev. Vet. Med. 84:310-323.

Harrison. C. 2013. Keeping up with Johne's: Practical opportunities for the control of Johne's disease in dairy cattle. A Nuffield (UK) Farming Scholarships Trust Report. Accessed Feb. 17, 2014. http://www.nuffieldinternational.org/rep_pdf/1375735526Charles -Harrison-report-2012.pdf.

Heffernan, C., L. Azbel-Jackson, J. Brownlie, and G. Gunn. 2016. Farmer attitudes and livestock disease: Exploring citizenship behaviour and peer monitoring across two BVD control schemes in the UK. PLoS One 11:e0152295.

Hood, B., and T. Seedsman. 2004. Psychosocial investigation of individual and community responses to the experience of Ovine Johne's Disease in rural Victoria. Aust. J. Rural Health 12:54-60.

Hop, G. E., A. G. J. Velthuis, and K. Frankena. 2011. Assessing Dutch farmers' incentives to join a voluntary Johne's disease programme. NJAS Wagening. J. Life Sci. 58:57-64.

Jansen, J., B. H. van den Borne, R. J. Renes, G. van Schaik, T. J. Lam, and C. Leeuwis. 2009. Explaining mastitis incidence in Dutch dairy farming: The influence of farmers' attitudes and behaviour. Prev. Vet. Med. 92:210-223.

JIC (Johne's Information Centre). 2010. General Johne's information-Test your knowledge. Accessed Feb. 17, 2014. http://www .johnes.org/knowledge.html.

Jubb, T. F., and J. Galvin. 2004. Effect of a test and control program for bovine Johne's disease in Victorian dairy herds 1992-2002. Aust. Vet. J. 82:228-232.

Kingham, L., and I. Links. 2012. Development of a group approach to facilitative vaccination for ovine Johne's disease (OJD) in New South Wales. Page 178 in 11th International Colloquium on Paratuberculosis Proc., Sydney, Australia. International Association for Paratuberculosis. http://www.paratuberculosis.net/proceedings/ proc11.pdf.

Krueger, R. A., and M. A. Casey. 2008. Focus Groups: A Practical Guide for Applied Research. Sage, Thousand Oaks, CA.

Leeuwis, C., and A. van den Ban. 2004. Communication for Rural Innovation: Rethinking Agricultural Extension. 3rd ed. Blackwell, Oxford, UK

Maxwell, J. A. 2012. A Realist Approach for Qualitative Research. Sage, Thousand Oaks, CA.

McAloon, C. G., Á. Macken-Walsh, L. Moran, P. Whytea, S. J. More, L. O'Gradya, and M. L. Doherty. 2017. Johne's disease in the eyes of Irish cattle farmers: A qualitative narrative research approach to understanding implications for disease management. Prev. Vet. Med. 141:7-13.

McKenna, S. L. B., G. P. Keefe, A. Tiwari, J. A. VanLeeuwen, and H. W. Barkema. 2006. Johne's disease in Canada part II: Disease impacts, risk factors and control programs for dairy producers. Can. Vet. J. 47:1089-1099.

Mishina, D., P. Katsel, S. T. Brown, E. C. Gilberts, and R. J. Greenstein. 1996. On the etiology of Crohn disease. Proc. Natl. Acad. Sci. USA 93:9816-9820.
Naser, S. A., G. Ghobrial, C. Romero, and J. F. Valentine. 2004 Culture of Mycobacterium avium subspecies paratuberculosis from the blood of patients with Crohn's disease. Lancet 364:1039-1044.

Nielsen, S. S. 2007. Danish control programme for bovine paratuberculosis. Cattle Pract. 15:161-168.

Nielsen, S. S. 2011. Dairy farmers' reasons for participation in the Danish control programme on bovine paratuberculosis. Prev. Vet. Med. 98:279-283.

Nightingale, C., K. Dhuyvetter, R. Mitchell, and Y. Schukken. 2008. Influence of variable milk quality premiums on observed milk quality. J. Dairy Sci. 91:1236-1244.

Norton, S., C. Heuer, and R. Jackson. 2009. A questionnaire-based cross-sectional study of clinical Johne's disease on dairy farms in New Zealand. N. Z. Vet. J. 57:34-43.

OJEMAP (Ontario Johne's Disease Education and Management Assistance Program). 2013. Johne's program - End of program testing summary. Accessed Feb. 17, 2014. http://www.johnes.ca/pdf \%20files/End\%20of\%20Program\%20Testing\%20Results.pdf.

Pike, T. 2008. Understanding behaviours in a farming context: Bridging theoretical and applied evidence together from across Defra and highlighting policy relevance and implications for future research. Accessed Feb. 17, 2014. http://archive.defra.gov .uk/evidence/statistics/foodfarm/enviro/observatory/research/ documents/ACEO \%20Behaviours\%20Discussion \% 20Paper\%20 (new\%20links).pdf.

Pratt, C., and S. Bowman. 2008. Principles of effective behavior change: Application to extension family educational programming. J. Ext. 46:5FEA2.

Rehman, T., K. McKemey, C. M. Yates, R. J. Cooke, C. J. Garforth, R. B. Tranter, J. R. Park, and P. T. Dorward. 2007. Identifying and understanding factors influencing the uptake of new technologies on dairy farms in SW England using the theory of reasoned action. Agric. Syst. 94:281-293.

Ridge, S. E., I. M. Baker, and M. Hannah. 2005. Effect of compliance with recommended calf-rearing practices on control of bovine Johne's disease. Aust. Vet. J. 83:85-90.

Ritter, C., J. Jansen, S. Roche, D. F. Kelton, C. L. Adams, K. Orsel, R. J. Erskine, G. Benedictus, T. J. G. M. Lam, and H. W. Barkema. 2017. Invited review: Determinants of farmers' adoption of management-based strategies for infectious disease prevention and control. J. Dairy Sci. 100:3329-3347.

Roche, S. M., A. Jones-Bitton, M. Meehan, M. Von Massow, and D. F. Kelton. 2015. Evaluating the effect of Focus Farms on Ontario dairy producers' knowledge, attitudes, and behavior toward control of Johne's disease. J. Dairy Sci. 98:5222-5240.

Sasaki, H. 2012. Farmer behaviour, agricultural management, and climate change. OECD, Paris, France.

Sergeant, E. S., S. S. Nielsen, and N. Toft. 2008. Evaluation of teststrategies for estimating probability of low prevalence of paratuberculosis in Danish dairy herds. Prev. Vet. Med. 85:92-106.

Sorge, U., D. Kelton, K. Lissemore, A. Godkin, S. Hendrick, and S. Wells. 2010a. Attitudes of Canadian dairy farmers toward a voluntary Johne's disease control program. J. Dairy Sci. 93:1491-1499.

Sweeney, R. W., M. T. Collins, S. M. Koets, A. P. McGuirk, and A. J. Roussel. 2012. Paratuberculosis (Johne's disease) in cattle and other susceptible species. ACVIM consensus statement. J. Vet. Intern. Med. 26:1239-1250.

Trier, L., S. S. Nielsen, and K. Krogh. 2012. Motivation of farmers to reduce between-herd transmission of paratuberculosis through repeated on-farm meetings with discussion on certification. Page 318 in 11th International Colloquium on Paratuberculosis Proc., Sydney, Australia. International Association for Paratuberculosis. http://www.paratuberculosis.net/proceedings/proc11.pdf.

Vaarst, M., B. Paarup-Laursen, H. Houe, C. Fossing, and H. J. Andersen. 2002. Farmers' choice of medical treatment of mastitis in Danish dairy herds based on qualitative research interviews. J. Dairy Sci. 85:992-1001.

Valeeva, N. I., T. J. Lam, and H. Hogeveen. 2007. Motivation of dairy farmers to improve mastitis management. J. Dairy Sci. 90:44664477. 
Wraight, M. D., J. McNeil, D. S. Beggs, R. K. Greenall, T. B. Humphris, R. J. Irwin, S. P. Jagoe, A. Jemmeson, W. F. Morgan, P. Brightling, G. A. Anderson, and P. D. Mansell. 2000. Compliance of Victorian dairy farmers with current calf rearing recommendations for control of Johne's disease. Vet. Microbiol. 77:429-442.

\section{Appendix A: Focus Group Discussion Guide-Dairy Producers}

\section{Introduction}

"Hi everyone. I would like to thank you all for taking the time today to join our discussion about Johne's disease. My name is [insert name] and I will be moderating the discussions today. [Insert name] will also be present to take notes on the discussion.

The goal today is to openly discuss your opinions and attitudes toward a variety of issues relating to Johne's disease and agricultural extension in Ontario. It is important to note that there are no right or wrong answers during these discussions; we are interested in your honest opinions, so please feel comfortable in expressing them.

I will be audio-recording the discussions today for data analysis. Our research team and a single professional transcriptionist will be the only ones with access to these recordings. All personal information will be kept confidential and at no point in time will we release any identifying information.

Just before we get started, I would like to mention a few housekeeping things. For your participation today you will receive $\$ 50$ cash at the end of the session. Please be sure to sign the attendance form indicating that you have received compensation. We also have some refreshments at the back of the room; please feel free to help yourself through the session. Once our discussion is over today I would appreciate it if you could refrain from discussing others people's opinions outside of the room to ensure confidentiality and privacy of everyone's comments. At any point during this session, you may refuse to answer questions or choose to withdraw from the study without consequences. I would also like to emphasize that we want to be sure to hear everyone's opinions today, so at certain points I may interrupt you or call on you to ensure everyone has a chance to speak. We will be wrapping things up today after about $2 \mathrm{~h}$.

Please keep in mind that participation is key to the success of a focus group, so I encourage you all to share your thoughts on each topic. My role here is to keep the discussion moving, keep us on time, and make sure everyone has a chance to speak.

If there are no questions, I would like to ask you to read and sign the consent form to participate in this study."

\section{Questions and Probes}

1. What comes to mind when you think about Johne's Disease?

- Do you feel Johne's disease is a problem for the Ontario dairy industry?

- How does Johne's disease rank in your priorities compared with other diseases?

2. When you think about implementing recommended management practices on your farm, what do you see as the main barriers to adopting these recommendations?

- What kinds of barriers do you see for someone who hasn't done these?

- Can you think of potential solutions to address these barriers?

- Do you feel Johne's disease is, or could be, a problem on your farm?

3. How do you think we can motivate producers to make changes to address Johne's disease?

- How do the actions of your peers affect what you do?

- What motivates you to make any sort of change on your farm?

4. Think about the people you consult to get new information on management decisions (i.e., veterinarian). How would you like them to provide you with new information?

- I prefer to get new information in writing. What is the most useful method for you?

\section{Appendix B: Focus Group Discussion Guide-Dairy Veterinarians}

\section{Introduction}

"Hi everyone. I would like to thank you all for taking the time today to join our discussion about Johne's disease. My name is [insert name] and I will be moderating the discussions today. [Insert name] will also be present to take notes on the discussion.

The goal today is to openly discuss your opinions and attitudes toward a variety of issues relating to producer perceptions of Johne's disease and agricultural extension in Ontario. It is important to note that there are no right or wrong answers during these discussions; we are interested in your honest opinions, so please feel comfortable in expressing them.

I will be audio-recording the discussions today for data analysis. Our research team and a single professional transcriptionist will be the only ones with access to these recordings. All personal information will be kept confidential and at no point in time will we release any identifying information. 
Just before we get started, I would like to mention a few housekeeping things. For your participation today you will receive $\$ 50$ cash at the end of the session. Please be sure to sign the attendance form indicating that you have received compensation. We also have some refreshments at the back of the room; please feel free to help yourself through the session. Once our discussion is over today I would appreciate it if you could refrain from discussing others people's opinions outside of the room to ensure confidentiality and privacy of everyone's comments. At any point during this session, you may refuse to answer questions or choose to withdraw from the study without consequences. I would also like to emphasize that we want to be sure to hear everyone's opinions today, so at certain points I may interrupt you or call on you to ensure everyone has a chance to speak. We will be wrapping things up today after about $2 \mathrm{~h}$.

Please keep in mind that participation is key to the success of a focus group, so I encourage you all to share your thoughts on each topic. My role here is to keep the discussion moving, keep us on time, and make sure everyone has a chance to speak.

If there are no questions, I would like to ask you to read and sign the consent form to participate in this study."

\section{Questions and Probes}

1. What comes to mind when you think about Johne's disease?
- Do you feel Johne's disease is a problem for the Ontario dairy industry?

- How do you think Johne's disease ranks in producers' priorities compared with other diseases?

2. When you think about recommending these kinds of management practices to producers, what do you see as the main barriers to adopting them?

- What kinds of barriers do you see for someone who hasn't done these?

- How do you think their attitude and knowledge factor in?

- Can you think of potential solutions to address these barriers?

3. How do you think we can motivate producers to make changes to address Johne's disease?

- How do you think the actions of other producers affect them?

4. Think about providing producers with new information on management practices. How do you think producers prefer to receive that information?

- How do you feel your preferences for receiving information affect how you deliver it?

- What kinds of extension/information delivery methods do you typically use? 